\title{
A stereoselective total synthesis of the novel triquinane sesquiterpene cucumin $\mathbf{E}$
}

\author{
Goverdhan Mehta* and Jayant D. Umarye \\ Department of Organic Chemistry, Indian Institute of Science, Bangalore 560 012, India
}

\begin{abstract}
A total synthesis of cucumin E, a recently isolated triquinane natural product with a new carbon framework, has been achieved. The key step is the flash vacuum pyrolysis (FVP)-induced cyclobutane fragmentation in a readily available pentacyclic caged dione to deliver the triquinane skeleton with functionalization in all the three five-membered rings suitable for further elaboration to the natural product.
\end{abstract}

During the past few decades, the linearly-fused triquinane sesquiterpenoids have been encountered in increasing numbers among diverse natural sources. Notable examples of the various tricyclo[6.3.0.0 $\left.0^{2,6}\right]$ undecane framework based triquinane skeleta, differing in methyl group disposition and level of functionalization, are hirsutic acid 1 (hirsutane type), capnellene $\mathbf{2}$ (capnellane type), ceratopicanol 3 (ceratopicane type) and pleurotellol 4 (pleurotellane type). The presence of an unusual tricarbocyclic core with skeletal, stereochemical and functional group diversity have sustained a high level of synthetic interest in this family of natural products. ${ }^{1}$ In 1998, research groups of Steglich and Anke have reported the isolation and structure determination of a new type of triquinane sesquiterpenes named cucumins E-G 5-7 from the mycelial cultures of agaric Macrocystidia cucumis (Pers ex Fr.). ${ }^{2}$ The stereostructures of cucumins $\mathrm{E}-\mathrm{G}$ were

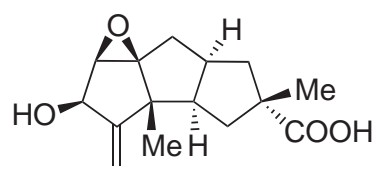

1

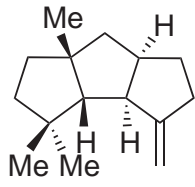

2

determined through incisive high-field NMR studies and these sesquiterpenes bear a close biogenetic relationship to the hirsutanes from which they are derived through a methyl group migration. Herein, we report the first total synthesis of cucumins, particularly of cucumin E $\mathbf{5}$, following an interesting variant of the photo-thermal metathetic approach to linear triquinanes delineated by us sometime ago. ${ }^{3}$

Pentacyclic dione $\mathbf{8}$, readily available from 1,2,3,4-tetrachloro-5,5-dimethoxycyclopentadiene and benzoquinone in two steps, ${ }^{4}$ on reductive dehalogenation and oxidation furnished 9, which we had identified as our key starting material. After some trials, it was possible to devise flash vacuum pyrolysis (FVP) conditions under which 9 underwent $[2+2]$-cycloreversion of the cyclobutane ring to furnish the triquinane bis-enone $\mathbf{1 0}^{5}$ quite satisfactorily,

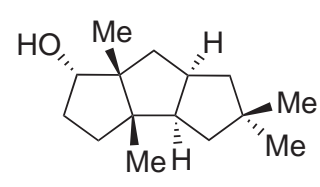

3<smiles>C=C1C(=O)C2OC23CC2C[C@@H]4CC(C)=C(CO)C4[C@@]2(C)C13C</smiles>

4

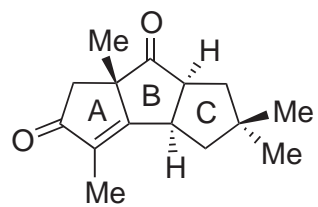

5<smiles>CC1=C2C3CC(C)(C)CC3C(O)C2(C)CC1=O</smiles>

6<smiles>[M]C12C[C@@H](O)CC1C1CC(C)(C)CC1=C2C</smiles>

7

Keywords: terpenes; polyquinanes; metathesis; pyrolysis; Wittig reaction.

* Corresponding author. E-mail: gm@orgchem.iisc.ernet.in 
Scheme 1. The important outcome was that the dimethyl acetal group of $\mathbf{9}$, necessary for our projected synthesis, was retained during the FVP conditions. Exposure of $\mathbf{1 0}$ to base established an equilibrium through back and forth double bond isomerizations and resulted in the desired epimerization at the ring junction to furnish a readily separable mixture $(4: 1)$ of the isomerized bisenone 11 and the epimerized cis,anti,cis-bis-enone 12. ${ }^{5}$ The bis-enone 11 could be further equilibrated in the presence of base to furnish 12, ensuring preparative access to the required cis, anti,cis-isomer.

Attention was now turned towards the installation of the four methyl groups on the triquinane $\mathbf{1 2}$ and relevant functional group adjustments. Catalytic hydrogenation of $\mathbf{1 2}$ and selective mono-Wittig olefination led to the ketone 13 (Scheme 1). Methylation of $\mathbf{1 3}$ was effected regioselectively and efficiently to furnish the gemdimethylated ketone $14{ }^{5}$ The carbonyl group was sought to be removed at this stage and, as direct deoxygenation methods were unsuccessful, 14 was reduced with lithium aluminum hydride to furnish 15 (5:1, exo:endo), Scheme 1. The Barton deoxygenation sequence ${ }^{6}$ on $\mathbf{1 5}$ delivered 16. ${ }^{5}$ The next task en-route to the cucumin skeleton was the introduction of the angular methyl group to generate the complete $\mathrm{C}_{15}$-carbon framework. For this purpose, the ketal moiety in $\mathbf{1 6}$ was deprotected to furnish $\mathbf{1 7}$. Angular methylation in $\mathbf{1 7}$ exhibited fair regioselectivity (2:1 in favour of C7 versus C9), an outcome that we had anticipated on account of the steric (methylation at C9

would lead to relative crowding in the gem-dimethyl bearing ring-C) and electronic (the deprotonation at $\mathrm{C} 7$ leads to a homoallylic carbanion $)^{7}$ considerations and $\mathbf{1 8}^{5}$ was obtained as the major product, Scheme 2 . The enone moiety in ring-A of $\mathbf{1 8}$ was established through allylic oxidation following the Sharpless ${ }^{8}$ catalytic selenium dioxide oxidation to give $19^{5}$ and further PDC oxidation to the enone 20 (Scheme 2). Rh(III)-mediated isomerization of the exocyclic double bond in $\mathbf{2 0}$ delivered cucumin E 5, whose spectral characteristics were exactly identical to the natural product as established through direct comparison. $^{2}$

In short, we have accomplished a total synthesis of the tricyclic natural product cucumin E 5, with good regioand stereochemical control, following a tactical modification of the photo-thermal metathesis based strategy that provides direct and rapid access to the ring-B functionalized triquinane framework.

\section{Acknowledgements}

We would like to thank Professor Steglich for the copies of the spectra of the natural product for comparison purposes. One of us (J.D.U.) thanks CSIR for the award of a Research Fellowship. We thank SIF at I.I.Sc. for high field NMR data.

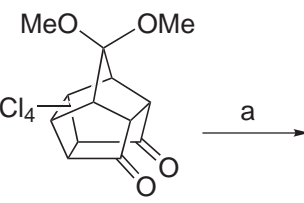

8

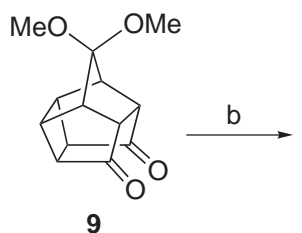

9

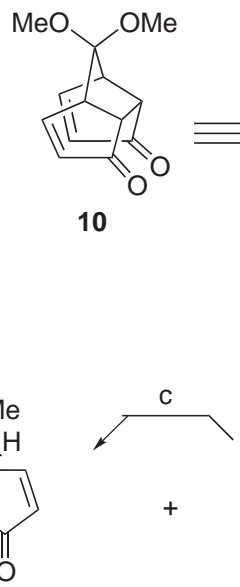

12<smiles>COC1(OC)[C@H](C=O)[C@]2(C)[C@@H]1C=C[C@H]2C</smiles><smiles>C=C1CC[C@H]2[C@@H]3C(=O)CC[C@@H]3C(OC)(OC)[C@H]12</smiles>

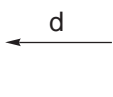

13 e

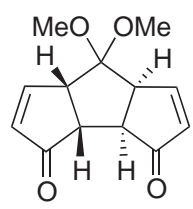

'

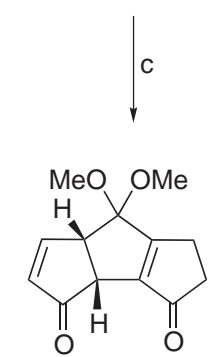

11

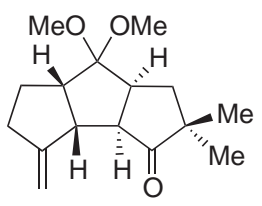

14

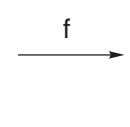

$\longrightarrow$

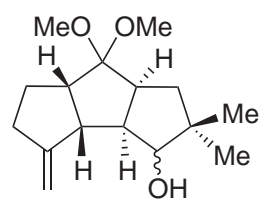

15

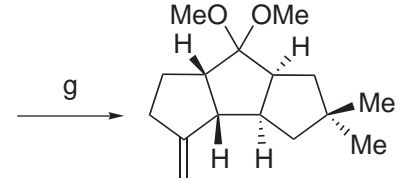

16

Scheme 1. Reagents and conditions: (a) i. Li, liq. $\mathrm{NH}_{3}, \mathrm{THF}, \mathrm{H}_{2} \mathrm{O}, 55 \%$; ii. $\mathrm{PCC}, \mathrm{NaOAc}, \mathrm{DCM}, 3 \mathrm{~h}, 50 \%$; (b) FVP, 590-610 ${ }^{\circ} \mathrm{C}$, $10^{-2} \mathrm{mmHg}, 65 \%$; (c) DBU, DCM, $24 \mathrm{~h}, \Delta$, quant. 11:12 (4:1); (d) i. $\mathrm{H}_{2}, 10 \% \mathrm{Pd} / \mathrm{C}, 1$ atm, EtOAc, rt, $1 \mathrm{~h}$, quant.; ii. $\mathrm{PPh}_{3}{ }^{+} \mathrm{CH}_{3} \mathrm{Br}^{-},{ }^{t} \mathrm{BuO}^{-} \mathrm{K}^{+}$, benzene, $5^{\circ} \mathrm{C}, 95 \%$ at $60 \%$ conversion; (e) $\mathrm{NaH}$ (5 equiv.), MeI (10 equiv.), THF, 8-10 h, 85-90\%; (f) LAH (excess), THF, 0.5 h, 90\%; (g) i. NaH (8 equiv.), $\mathrm{CS}_{2}$, imidazole (cat.), MeI, THF, 5 h, $\Delta, 80 \%$. ii. TBTH-AIBN, toluene, $\Delta, 10 \mathrm{~min}, 70-80 \%$. 


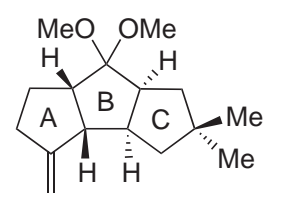

16

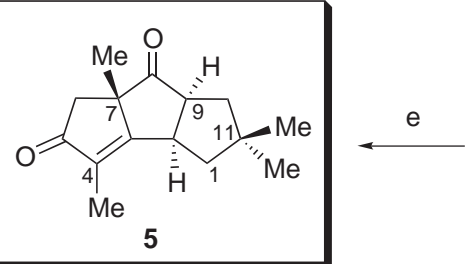

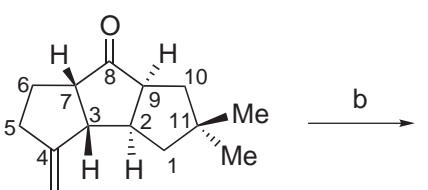

17

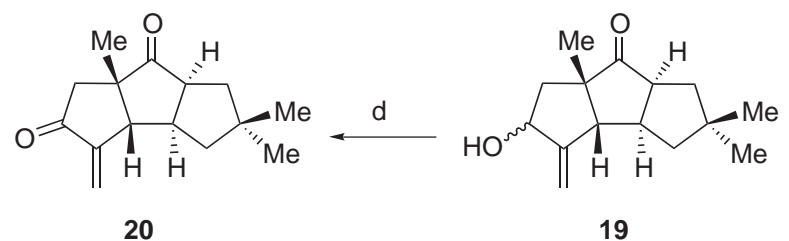

Scheme 2. Reagents and conditions: (a) Amberlyst-15, aq. acetone, quant.; (b) LDA (3 equiv.), MeI (10 equiv.), THF, $-10^{\circ} \mathrm{C}$, 10 min, (2:1, mixture of regioisomers), 70\%; (c) $\mathrm{SeO}_{2}, \mathrm{TBHP}, \mathrm{DCM}, \mathrm{rt}, 4 \mathrm{~h}, 90 \%$; (d) PDC, DCM, rt, 3 h, 70\%; (e) $\mathrm{RhCl}$, EtOH (degassed), $\Delta, 1 \mathrm{~h}, 80 \%$.

\section{References}

1. Recent reviews: (a) Mehta, G.; Srikrishna, A. Chem. Rev. 1997, 97, 671. (b) Singh, V.; Thomas, B. Tetrahedron 1998, 54, 3647.

2. Hellwig, V.; Dasenbrock, J.; Schumann, S.; Steglich, W.; Leonhardt, K.; Anke, T. Eur. J. Org. Chem. 1998, 73.

3. (a) Mehta, G.; Reddy, A. V.; Srikrishna, A. Tetrahedron Lett. 1979, 20, 4863; (b) Mehta, G.; Srikrishna, A.; Reddy, A. V.; Nair, M. S. Tetrahedron 1981, 37, 4543; (c) Mehta, G.; Murthy, A. N.; Reddy, D. S.; Reddy, A. V. J. Am. Chem. Soc. 1986, 108, 3443.

4. (a) Eaton, P. E.; Or, Y. S.; Branca, S. J.; Ravishankar, B. K. Tetrahedron 1986, 42, 1621; (b) Fessner, W.-D.; Prinzbach, H. Tetrahedron 1986, 42, 1797.

5. All new compounds reported here were racemic and characterized on the basis of spectroscopic data (IR, ${ }^{1} \mathrm{H}$ and ${ }^{13} \mathrm{C}$ NMR, mass) and elemental analyses. Selected spectral data. 10: $\mathrm{mp} 149^{\circ} \mathrm{C}$; ${ }^{1} \mathrm{HNMR}\left(300 \mathrm{MHz}, \mathrm{CDCl}_{3}\right): \delta 7.5(\mathrm{dd}, J=5.8$, $1.8 \mathrm{~Hz}, 2 \mathrm{H}), 5.97$ (dd, $J=5.8,2.4 \mathrm{~Hz}, 2 \mathrm{H}), 3.54$ (br s, 2H), 3.4 (s, 3H), 3.3 (s, 3H), 3.2 (br s, $2 \mathrm{H}) ;{ }^{13} \mathrm{C} \mathrm{NMR}(75 \mathrm{MHz}$, $\left.\mathrm{CDCl}_{3}\right) \delta 207.1,161.7,135.2,106.7,54.2,51.2,49.6,48.6$; MS: $m / z 233\left(\mathrm{M}^{+}-1\right) .12: \mathrm{mp} 148^{\circ} \mathrm{C} ;{ }^{1} \mathrm{H}$ NMR $(300 \mathrm{MHz}$, $\left.\mathrm{CDCl}_{3}\right): \delta 7.56(\mathrm{dd}, J=5.4,3.3 \mathrm{~Hz}, 2 \mathrm{H}), 6.21(\mathrm{dd}, J=5.7$,
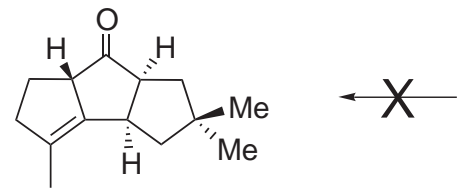

17

(i)

$1.8 \mathrm{~Hz}, 2 \mathrm{H}), 3.5(\mathrm{~m}, 2 \mathrm{H}), 3.28(\mathrm{~s}, 6 \mathrm{H}), 2.88(\mathrm{~m}, 2 \mathrm{H}) ;{ }^{13} \mathrm{C} \mathrm{NMR}$ $\left(75 \mathrm{MHz}, \mathrm{CDCl}_{3}\right) \delta$ 208.3, 161.3, 134.2, 108.2, 53.6, 50.0, 49.2; MS: $m / z 234\left(\mathrm{M}^{+}\right)$. 16: ${ }^{1} \mathrm{H}$ NMR (300 MHz, $\left.\mathrm{CDCl}_{3}\right)$ : $\delta 4.76(\mathrm{br} \mathrm{s}, 2 \mathrm{H}), 3.21(\mathrm{~s}, 3 \mathrm{H}), 3.14(\mathrm{~s}, 3 \mathrm{H}), 2.8-2.76(\mathrm{~m}, 2 \mathrm{H})$, 2.55-2.4 (m, 3H), 2.29-2.2 (m, 1H), $1.89(\mathrm{dd}, J=12.6,9 \mathrm{~Hz}$, $1 \mathrm{H}), 1.76-1.6(\mathrm{~m}, 3 \mathrm{H}), 1.34-1.23(\mathrm{~m}, 2 \mathrm{H}), 1.07$ (s, 3H), 0.9 (s, 3H); $\left.{ }^{13} \mathrm{C} \mathrm{NMR} \mathrm{(75} \mathrm{MHz,} \mathrm{CDCl}_{3}\right) \delta 158.4,110.4,103.9$, 54.2, 52.2, 50.5, 50.1, 49.4, 48.7, 48.0, 42.0, 40.5, 33.4, 29.3, 28.2, 26.8; MS: $m / z 249\left(\mathrm{M}^{+}-1\right)$. 18: ${ }^{1} \mathrm{H}$ NMR $(300 \mathrm{MHz}$, $\left.\mathrm{CDCl}_{3}\right): \delta 4.96($ br s, $1 \mathrm{H}), 4.92($ br s, $1 \mathrm{H}), 2.98-2.89(\mathrm{~m}, 1 \mathrm{H})$, 2.62-2.5 (m, 1H), 2.5 (br s, 1H), 2.4-2.34 (m, 2H), 1.93-1.83 $(\mathrm{m}, 2 \mathrm{H}), 1.76(\mathrm{ddd}, J=13.2,9.9,1.5 \mathrm{~Hz}, 1 \mathrm{H}), 1.5-1.6(\mathrm{~m}$, $2 \mathrm{H}), 1.16(\mathrm{dd}, J=12.3,8.7 \mathrm{~Hz}, 1 \mathrm{H}), 1.17(\mathrm{~s}, 3 \mathrm{H}), 1.04(\mathrm{~s}$, $3 \mathrm{H}), 0.96(\mathrm{~s}, 3 \mathrm{H}) ;{ }^{13} \mathrm{C} \mathrm{NMR}\left(75 \mathrm{MHz}, \mathrm{CDCl}_{3}\right.$ ) $\delta 225.2,157.1$, 106.3, 58.8, 58.3, 52.2, 48.9, 46.5, 43.3, 41.1, 37.58, 32.5, 29.0, 28.2, 22.8; MS: $m / z 217$ (M+1). 20: ${ }^{1} \mathrm{H}$ NMR $(300 \mathrm{MHz}$, $\left.\mathrm{CDCl}_{3}\right): \delta 6.11(\mathrm{~d}, J=2.3 \mathrm{~Hz}, 1 \mathrm{H}), 5.5(\mathrm{~d}, J=2.3 \mathrm{~Hz}, 1 \mathrm{H})$ 3.1 (ddd, $J=10 \mathrm{~Hz}, 1 \mathrm{H}), 2.86(\mathrm{~m}, 1 \mathrm{H}), 2.66(\mathrm{~m}, 1 \mathrm{H}), 2.57$ (d, $J=19 \mathrm{~Hz}, 1 \mathrm{H}), 2.24$ (d, $J=19 \mathrm{~Hz}, 1 \mathrm{H}), 1.97$ (ddd, $J=13$, 8, $1.5 \mathrm{~Hz}, 1 \mathrm{H}), 1.84$ (ddd, $J=13,9.9,1.5 \mathrm{~Hz}, 1 \mathrm{H}), 1.64$ (dd, $J=12.9,7.5 \mathrm{~Hz}, 1 \mathrm{H}), 1.46(\mathrm{dd}, J=12.9,7.5 \mathrm{~Hz}$, $1 \mathrm{H}), 1.26(\mathrm{~s}, 3 \mathrm{H}), 1.07(\mathrm{~s}, 3 \mathrm{H}), 0.99(\mathrm{~s}, 3 \mathrm{H}) ;{ }^{13} \mathrm{C} \mathrm{NMR}$ $\left(75 \mathrm{MHz}, \mathrm{CDCl}_{3}\right) \delta 221.7,204.1,148.6,119.2,55.7,52.2$, 51.5, 48.5, 47.8, 46.3, 43.4, 41.7, 28.8, 28.0, 23.1; MS: $m / z$ $232\left(\mathrm{M}^{+}\right)$.

6. (a) Barton, D. H. R.; McCombie, S. W. J. Chem. Soc., Perkin Trans. 1 1975, 1, 1574; (b) Tatsuta, K.; Akimoto, K.; Kinoshita, M. J. Am. Chem. Soc. 1979, 101, 6116.

7. In order to ensure regioselectivity during the key angular methylation reaction, it was proposed to isomerize the

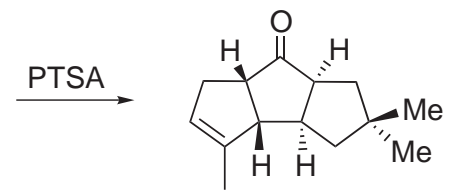

(ii)

exocyclic double bond in $\mathbf{1 7}$ to endocyclic position as in (i) to promote the formation of the delocalized carbanion. However, efforts to relocate the double bond in $\mathbf{1 7}$ led only to (ii).

8. Sharpless, K. B.; Chabaud, B.; Warpehoski, M. A. J. Org. Chem. 1982, 47, 2897. 